\title{
The development of a simple turnout conversion force check meter
}

\author{
K. Yasuoka ${ }^{1}$, T. Kaneko ${ }^{1}$, M. Iikura ${ }^{1}$, S. Mochizuki ${ }^{2}$, \\ K. Numata ${ }^{2} \&$ H. Teramoto ${ }^{3}$ \\ ${ }^{1}$ East Japan Railway Company, Japan \\ ${ }^{2}$ Sankosha Co. Ltd., Japan \\ ${ }^{3}$ Tokyo Sokki Kenkyujo Co. Ltd., Japan
}

\begin{abstract}
The management of the conversion force of turnout, including of the point machine, is an important element for safety and stable transportation. Conversion force is managed by measuring torque or by the method of indirect measurement using voltage and current of the point machine. However, both kinds of data are based on the conversion force of the whole turnout including point machine. We cannot know which point machine or point part has trouble from that data. We then examined how to identify which is the trouble part and manage the conversion force concerning turnout, machine and point. It is possible to know the conversion force of a whole turnout to measure by using an existing axial tension meter into the connection section of turnout and equipment of point machine or the strain meter on the equipment of the point machine. The setup of this measurement apparatus takes time, and also these methods require adjustments to the equipment of the point machine before and after measurement. Then, a conversion force check meter, which can be attached to a point machine with a clip, is developed. This check meter can be mounted with the clip in a short time and does not require readjustment of the equipment of the point machine before and after measurement.
\end{abstract}

Keywords: conversion force, check meter, point machine, turnout, strain gauge. 


\section{Introduction}

Maintenance management of turnout and point machine is an important element of the safe and stable transportation for railway traffic.

This is because, as is a moving part, failure tends to occur there and is easily influenced by environmental conditions. Japanese turnouts consist of point part and crossing part and use point machine as conversion power source.

It requires much time to find the failed part when some trouble occurs at a turnout, becoming a factor in upsetting the stability of railway traffic. So, we developed a measuring instrument, the conversion force check meter, which can measure the conversion power of point part (the moving part of tongue rails), in a short time in order to specify the point of failure around point part and point machine.

\section{Maintenance management of point machine in JRE}

\subsection{Varieties of point machine}

The conventional lines of JR East use point machines [1] using electricity, and about $84 \%$ are called NS type point machine. The features of NS type point machine are as follows:

1) The indirect lock system and gear mechanism for conversion

The composition of a typical Japanese turnout and point machine is shown in figure 1 . The point machine moves a moving rod through the internal conversion gear, and converts the tongue rails (figure 2). The tipping gap between a tongue rail and a stock rail is detected by the position of the lock piece in the point machine. The lock piece indicates indirectly the positional relation of the lock rod and the tongue rail (figure 3 ).

And when a tongue rail completes conversion and the lock piece in a point machine is settled in a predetermined position, tongue rails are locked in a point machine.

The tipping gap between a tongue rail and a stock rail is detected by the position of a lock piece in a point machine. The rock piece indicates indirectly the positional relation of the lock rod and a tongue rail (figure 3).

\section{In Japan (Indirect locking system)}

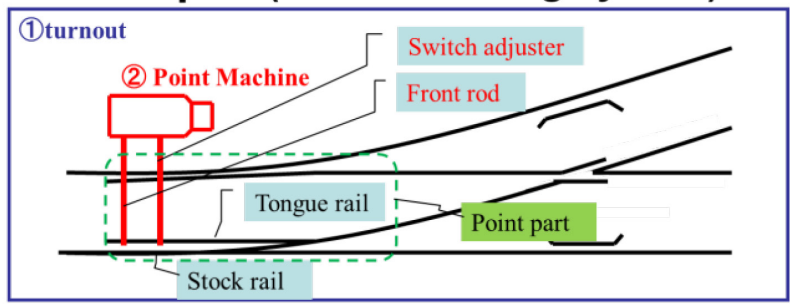

Figure 1: Japanese turnout and point machine constitution. 


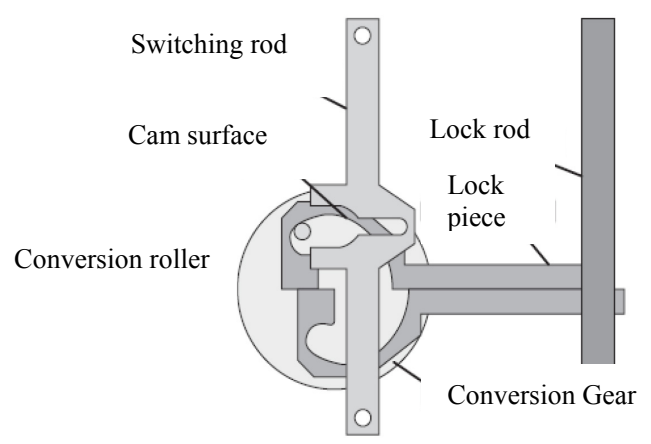

Figure 2: $\quad$ Lock and conversion gear system in the point machine.

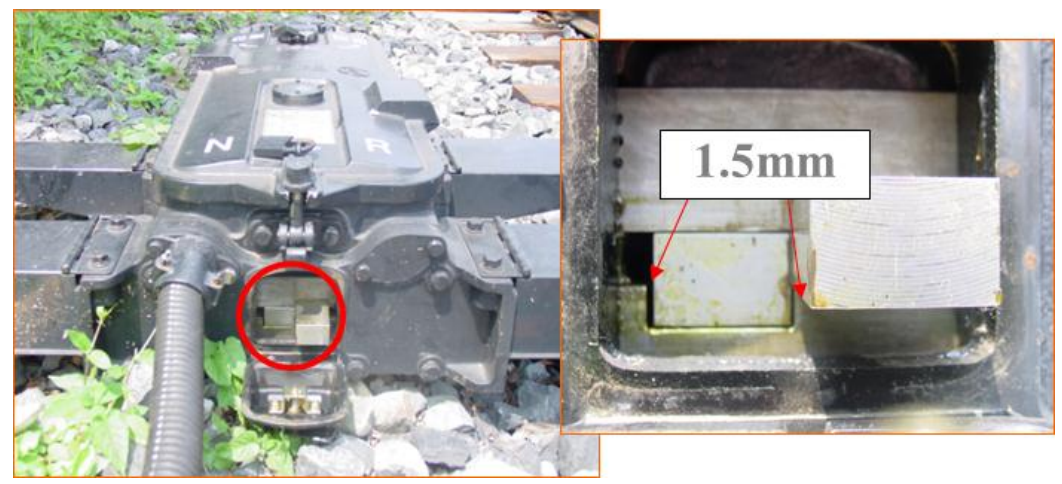

Figure 3: $\quad$ Lock piece.

2) Source of power is single phase $\mathrm{AC}$ induction motor

The point machine uses a single phase $100 \mathrm{~V}$ AC induction motor to fit Japanese electricity requirements.

\subsection{Inspection of the point machine}

The main items to be inspected and adjusted periodically with the point machine are shown in Table 1.

Besides periodical inspection, the point machine is maintained when the alarm from a monitoring system occurs or trouble happens. Load torque, an equivalent for conversion power, measures the power of gear rotation in the point machine, so load torque is the combined value of the power needed inside the point part and the point machine. Moreover, in some cases along major lines continuous monitoring is also carried out. But load torque from monitoring system is also combined power. Since the measured conversion power is combined power, it cannot divide and need power to where it is needed when a conversion failure occurs. 
Table 1: The main items of point machine inspection.

\begin{tabular}{|l|l|l|l|}
\hline & $\begin{array}{l}\text { Items of } \\
\text { inspection }\end{array}$ & $\begin{array}{l}\text { Cyclic } \\
\text { inspection } \\
\text { schedule }\end{array}$ & Point to be checked \\
\hline 1 & $\begin{array}{l}\text { Touched power } \\
\text { right and wrong }\end{array}$ & Once a year & $\begin{array}{l}\text { The power of which the tongue rail and the stock } \\
\text { rail touch is suitable. }\end{array}$ \\
\hline 2 & $\begin{array}{l}\text { Proper lock } \\
\text { position right and } \\
\text { wrong }\end{array}$ & Once a year & $\begin{array}{l}\text { Detection of tipping gap between tongue rail and } \\
\text { stock rail. }\end{array}$ \\
\hline 3 & $\begin{array}{l}\text { Power supply and } \\
\text { control voltage }\end{array}$ & $\begin{array}{l}\text { Once in two } \\
\text { years }\end{array}$ & Voltage to be within a rated value. \\
\hline 4 & $\begin{array}{l}\text { Operating current } \\
\text { Once in two }\end{array}$ & Current to be within a rated value. \\
\hline 5 & Operation time & When needed & Conversion time to be suitable. \\
\hline 6 & $\begin{array}{l}\text { Load torque } \\
\text { measurement }\end{array}$ & When needed & Load Torque to be within a rated value. \\
\hline 7 & Function test & When needed & $\begin{array}{l}\text { Order from an interlocking system and indication } \\
\text { to an interlocking system to be suitable. }\end{array}$ \\
\hline
\end{tabular}

\subsection{Conventional conversion force measurement}

Two methods of measurement of combined conversion power are shown below.

1) Monitoring system

Monitoring system [2] uses voltage and current.

2) Handle-type torque meter

The handle-type torque meter [3] (figure 4) is often used when the trouble occurs. We put the torque meter into the handle loading slot on the point machine. We manage the torque data by a threshold value. When measured torque data exceeds the threshold value, we cannot know whether there is damage inside the point machine or if conversion load of point part is increasing. The handle of torque meter records the inner memory every 180 degrees.

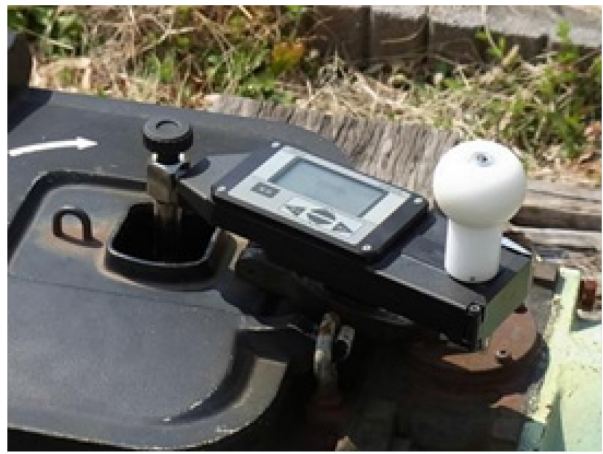

Figure 4: Handle-type torque meter. 
There is also method of measuring the conversion power of tongue rails, using the general-purpose strain gauge (figure 5) or the exclusive axial tension meter (figure 6).

Wire gauge

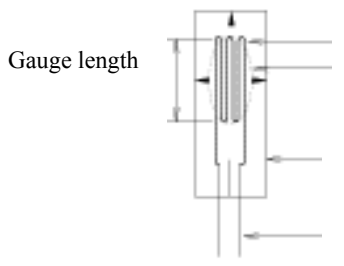

Adhesive Cover Film
Foil gauge
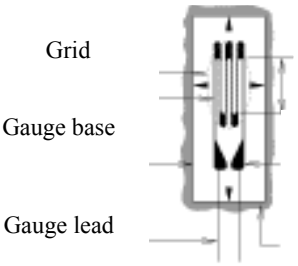

Gauge length

Gauge tab

Adhesive

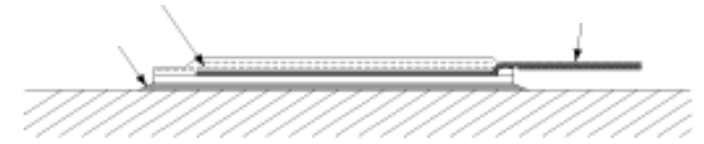

Figure 5: Strain gauge.

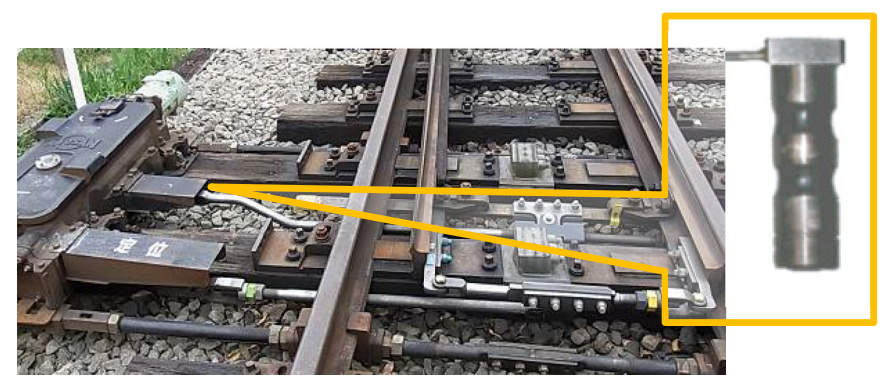

Figure 6: Axial tension meter.

Measurement using the strain gauge or the exclusive axial tension meter is difficult within the limited time between the trains.

The following detail the demerits.

1) The strain gauge

The sensing part must be abraded to obtain a flat surface for mounting the strain gauge. In addition, a measuring instrument which receives electrical signals from the strain gauge is needed.

2) The exclusive axial tension meter

Readjustment is required after the measurement, because the exclusive axial tension meter is inserted in the connecting part between the switch adjuster and the point machine in place of a pin. 


\section{Manufacture and verification of conversion power checker}

As mentioned above, it is difficult to measure easily and quickly using the existing measuring instrument in order to measure the conversion power of point part.

Therefore, we decided to develop a conversion power check meter which can solve these problems. This measure should:

1) Not require adjustment after measurement.

2) Require minimum time to prepare for measurement.

3) Have $90 \%$ or more measurement accuracy compared with an exclusive axial tension meter.

\subsection{Selection of a measuring method}

As a measuring method, the frictional strain gauge [4] (figure 7), which does not need a measuring surface to be abraded, was selected.

Its features are as follows:

1) Attaches to structure by magnet and measures strain by friction.

2) Removal of paint is unnecessary.

3) Easily attached and detached.

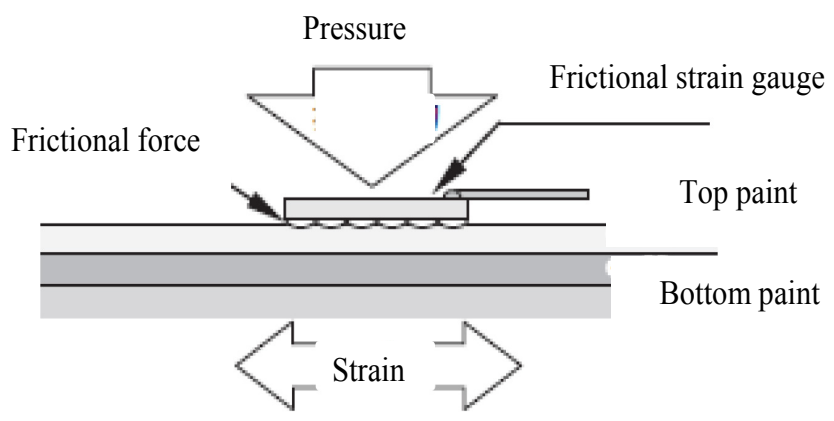

Figure 7: Frictional strain gauge.

\subsection{The method of fixation}

The full bridge method (axial tension) is generally used, when measuring rod-shaped axial tension by a strain gauge. The full bridge method (axial tension) uses strain gauges of 2 axial directions on either side of the rod and measures strain of tension and compression of the rod. Therefore, this trial product attached frictional type strain gauges of 2 axial directions on either side of the rod. Three fixing methods were proposed for the measuring instrument. Contents and comparison of each are shown in Table 2. The clip type was selected for this case and trial production and verification were performed. 
Table 2: Comparison examination of the fixation method.

\begin{tabular}{l|l|l|l}
\hline $\begin{array}{l}\text { Fixing } \\
\text { method }\end{array}$ & Pros & Cons & Valuation \\
\hline \hline Magnet & Proven form. & $\begin{array}{l}\text { Conversion cost is } \\
\text { high. } \\
\text { Need time for } \\
\text { conversion period. }\end{array}$ & Not good \\
\hline Clip & $\begin{array}{l}\text { Attachment and } \\
\text { detachment are easy. } \\
\text { Reasonable price }\end{array}$ & $\begin{array}{l}\text { Need to test duration } \\
\text { of clip spring. }\end{array}$ & Excellent \\
\hline Ring & $\begin{array}{l}\text { More accurate } \\
\text { measurement is possible } \\
\text { by keeping constant } \\
\text { pressure between gauge } \\
\text { and structure. }\end{array}$ & $\begin{array}{l}\text { Expensive. } \\
\text { Manufacture is } \\
\text { complex. }\end{array}$ & Good \\
\hline
\end{tabular}

\subsection{Field test}

The trial product was examined on a training line.

1) Measured items

The trial product is attached at points 1 to 4 and the measured values are compared with an existing axial tension meter (figure 8).

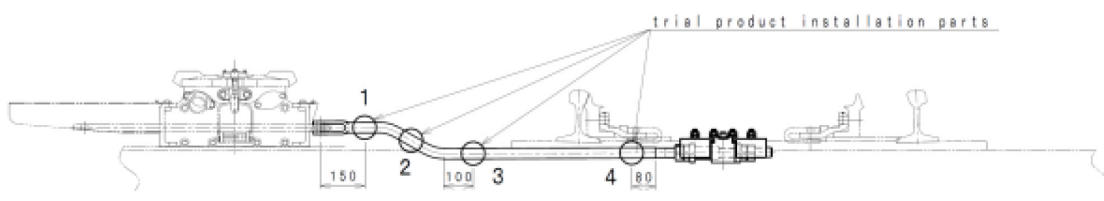

Figure 8: Trial product instalment parts.

2) Examination results

The measured result is shown in Table 3 .

In the case of the trial product is placed on 1, measured values approximated the axial tension meter's values (figure 9).

Table 3: Examination results.

\begin{tabular}{l|c|c||c|c}
\hline No. & $\begin{array}{c}\text { Conversion } \\
\text { direction }\end{array}$ & $\begin{array}{c}\text { Method of } \\
\text { conversion }\end{array}$ & $\begin{array}{c}\text { Installation } \\
\text { part }\end{array}$ & $\begin{array}{c}\text { Measurement } \\
\text { accuracy }\end{array}$ \\
\hline \hline No. 1 & One round trip & Electric conversion & 1 & Excellent \\
\hline No. 2 & One round trip & Electric conversion & 2 & Not good \\
\hline No. 3 & One round trip & Electric conversion & 3 & Good \\
\hline No. 4 & One round trip & Electric conversion & 4 & Good \\
\hline
\end{tabular}




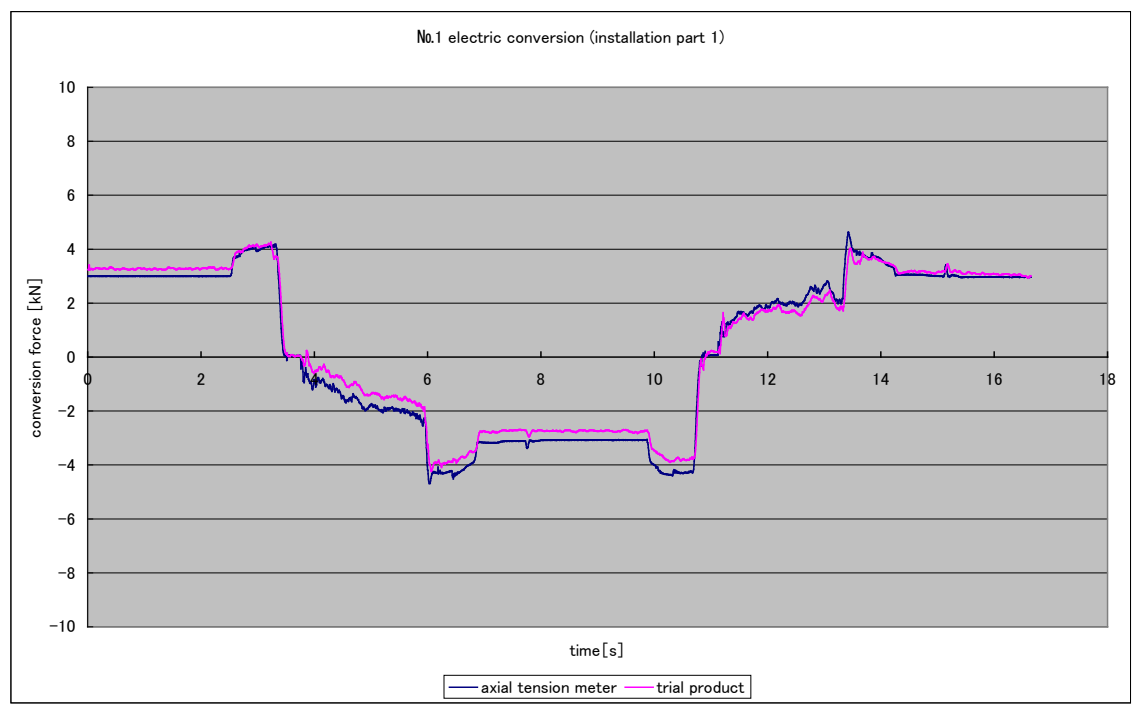

Figure 9: Comparison of conversion force data between axial tension meter and trial product (No. 1).

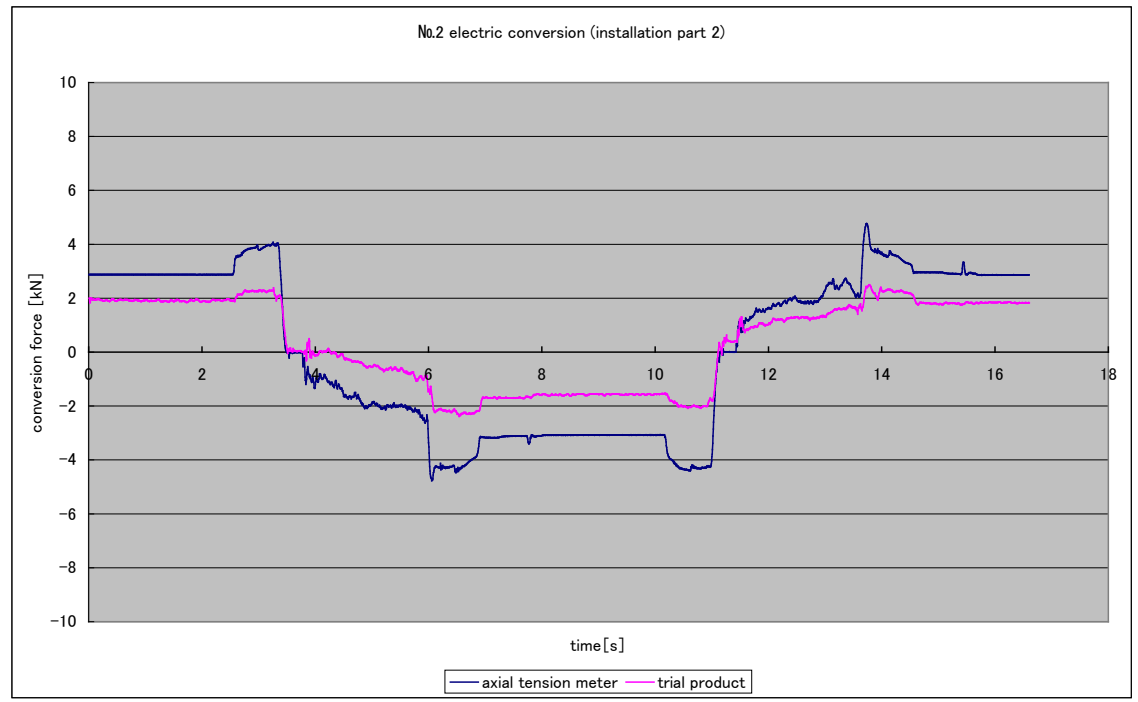

Figure 10: Comparison of conversion force data between axial tension meter and trial product (No. 2). 


\section{Conclusion}

As a result of examination of the trial product, it nearly fulfilled the requirements. Since this trial product can be used as a conversion check meter, failed parts can be divided into point part and point machine in a shorter time. I would like to perform the following verifications and work toward practical use of this measuring instrument.

1) Verification of durability of measuring instrument.

2) Verification of various point parts and point machines.

Simultaneously, the standard value of the conversion power of point parts and point machines is a desk-study value, and we also will utilize the measuring instrument towards establishment of standard value suitable for actual conditions.

\section{References}

[1] Hiroshi Yoshimura \& Saburo Yoshikoshi, Railway signal (Chapter 4). Topics in Point machine, Koyusya: Nagoya Japan, pp. 95-135, 1969.

[2] Nobuo Obata, Kenzi Mori \& Tunehiro Ichikura, JR East Technical review (No. 32). Special edition paper, East Japan Railway Company: Tokyo Japan, 2010.

[3] Tetsuden Co. Ltd, Maintenance tools, Japan, www.tetsuden.com/pdf/ maintenance.pdf.

[4] Tokyo Sokki kenkyusjo Co. Ltd, Catalog, Japan, pp. 19-26, 2013-2014. http://www.tml.jp/catalog/book_210-0229. 